\title{
Glutamate Released from Glial Cells Synchronizes Neuronal Activity in the Hippocampus
}

\author{
María Cecilia Angulo, ${ }^{1,2}$ Andreï S. Kozlov, ${ }^{1}$ Serge Charpak, ${ }^{1}$ and Etienne Audinat ${ }^{1}$ \\ ${ }^{1}$ Laboratoire de Neurophysiologie et Nouvelles Microscopies, Institut National de la Santé et de la Recherche Médicale U603, Centre National de la \\ Recherche Scientifique FRE 2500, Ecole Supérieure de Physique et Chimie Industrielles, 75005 Paris, France, and ${ }^{2}$ Centro Internacional de Física, Edificio \\ Manuel Ancízar, Ciudad Universitaria, Bogotá, Colombia
}

Glial cells of the nervous system directly influence neuronal and synaptic activities by releasing transmitters. However, the physiological consequences of this glial transmitter release on brain information processing remain poorly understood. We demonstrate here in hippocampal slices of 2 - to 5 -week-old rats that glutamate released from glial cells generates slow transient currents (STCs) mediated by the activation of NMDA receptors in pyramidal cells. STCs persist in the absence of neuronal and synaptic activity, indicating a nonsynaptic origin of the source of glutamate. Indeed, STCs occur spontaneously but can also be induced by pharmacological tools known to activate astrocytes and by the selective mechanical stimulation of single nearby glial cells. Bath application of the inhibitor of the glutamate uptake DL-threo- $\beta$-benzyloxyaspartate increases both the frequency of STCs and the amplitude of a tonic conductance mediated by NMDA receptors and probably also originated from glial glutamate release. By using dual recordings, we observed synchronized STCs in pyramidal cells having their soma distant by $<100 \mu \mathrm{m}$. The degree of precision $(<100 \mathrm{msec})$ of this synchronization rules out the involvement of calcium waves spreading through the glial network. It also indicates that single glial cells release glutamate onto adjacent neuronal processes, thereby controlling simultaneously the excitability of several neighboring pyramidal cells. In conclusion, our results show that the glial glutamate release occurs spontaneously and synchronizes the neuronal activity in the hippocampus.

Key words: astrocytes; NMDA receptors; ambient glutamate; neuron-glia interactions; glutamate transporters; dual recordings

\section{Introduction}

In the brain, glial cells are in close apposition with neurons, and synapses are very often ensheathed by glia processes (Schikorski and Stevens, 1997; Grosche et al., 1999; Ventura and Harris, 1999; Auld and Robitaille, 2003). This anatomical feature allows glial cells to sense neuronal activity with receptors specific for various neurotransmitters (for review, see Verkhratsky et al., 1998; Haydon, 2001). However, glial cells can also release neuroactive transmitters (for review, see Nedergaard et al., 2002; Auld and Robitaille, 2003; Newman, 2003). Synapses are thus now considered tripartite structures, where glial cells activated by the release of neurotransmitters from the presynaptic neuronal element can feed back onto both presynaptic and postsynaptic neurons by releasing "gliotransmitters" (Araque et al., 1999, 2001).

The most widely studied gliotransmitter is the excitatory amino acid glutamate. Its release evoked by the selective activa-

\footnotetext{
Received Feb. 10, 2004; revised June 8, 2004; accepted June 26, 2004.

This work was supported by the Fondation pour la Recherche Médicale (INE20001117003/1) and the Avenir Program of the Institut National de la Santé et de la Recherche Médicale. A.S.K. was supported by the International Brain Research Organization. We thank M. Hanafi for technical assistance and Dr. C. Pouzat for comment on statistics. M.C.A. performed preliminary experiments with Dr. G. Carmignoto at Padova University.

Correspondence should be addressed to Etienne Audinat, Laboratoire de Neurophysiologie et Nouvelles Microscopies, Institut National de la Santé et de la Recherche Médicale U603, Centre National de la Recherche Scientifique FRE 2500, Ecole Supérieure de Physique et Chimie Industrielles, 75005 Paris, France. E-mail: etienne.audinat@espci.fr.

DOI:10.1523/JNEUROSCI.0473-04.2004

Copyright $\odot 2004$ Society for Neuroscience $\quad 0270-6474 / 04 / 246920-08 \$ 15.00 / 0$
}

tion of glial cells has been originally demonstrated in cocultures of astrocytes and neurons where it activates neuronal ionotropic as well as metabotropic glutamate receptors and modulates synaptic transmission (Parpura et al., 1994; Araque et al., 1998a,b, 2000; Parpura and Haydon, 2000). In acute slices of the hippocampus and of the cerebellum, direct depolarization of glial cells also modulates the frequency of miniature postsynaptic currents by activating ionotropic glutamate receptors (Kang et al., 1998; Brockhaus and Deitmer, 2002). Calcium imaging experiments in hippocampal slices have also shown that activation of astrocytes by neuronal stimulations or applications of glutamate agonists, or of prostaglandin $\mathrm{E}_{2}\left(\mathrm{PGE}_{2}\right)$, induces calcium signals in neighboring neurons, which are blocked by antagonists of ionotropic glutamate receptors and, thus, probably result from a release of glutamate by astrocytes (Pasti et al., 1997; Bezzi et al., 1998).

In addition to their mobilization in response to synaptic activity, glial cells also display some forms of intrinsic activity in the absence of neuronal stimulation. Indeed, in acute slices of the cortex, hippocampus, and thalamus, intracellular calcium oscillations have been observed in astrocytes in the absence of neuronal activity (Parri et al., 2001; Aguado et al., 2002; Nett et al., 2002). Furthermore, spontaneous waves of calcium oscillations can propagate between neighboring thalamic astrocytes and modulate the activity of neurons located along the wave path (Parri et al., 2001). Therefore, it seems that glial cells can also 
shape neuronal activity in response to interactions within glial cell networks as they do in response to neuronal activity. In the present study, we aimed to determine whether the excitability of hippocampal pyramidal neurons is influenced by the spontaneous activity of glial cells. We focused on glutamatergic transmission and found that, indeed, pyramidal neurons are excited by glutamate release resulting from the spontaneous activity of glial cells and that neighboring neurons are synchronized by this glial activity.

\section{Materials and Methods}

Slice preparation. Hippocampal slices $(300-380 \mu \mathrm{m})$ were prepared from Wistar rats at postnatal day 11 (P11) to P40 (Edwards et al., 1989). Immediately after slicing, the $\mathrm{CA} 3$ region was cut at $4^{\circ} \mathrm{C}$ in the presence of $1 \mu \mathrm{M}$ tetrodotoxin (TTX). Then, the slices were transferred to an incubation chamber and maintained either at room temperature or at $34^{\circ} \mathrm{C}$ in an oxygenated physiological solution containing (in $\mathrm{mM}$ ): $126 \mathrm{NaCl}, 2.5$ $\mathrm{KCl}, 1.25 \mathrm{NaH}_{2} \mathrm{PO}_{4}, 26 \mathrm{NaHCO}_{3}, 1 \mathrm{CaCl}_{2}, 2 \mathrm{MgCl}_{2}, 20$ glucose, 5 pyruvate. Incubating the slices at different temperatures did not influence the presence of both tonic and transient glutamatergic currents; thus, data were pooled.

For recordings, slices were perfused in a chamber at $2-3 \mathrm{ml} / \mathrm{min}$ with a similar physiological solution containing $2 \mathrm{mM} \mathrm{CaCl}_{2}, 0 \mathrm{~mm} \mathrm{MgCl}$, and a $100 \mu \mathrm{M}$ concentration of the $\mathrm{GABA}_{\mathrm{A}}$ antagonist picrotoxin. Most of the recordings were also performed in the presence of $0.5 \mu \mathrm{M}$ TTX, which blocks action potential propagation in neurons (data not shown), and at $34^{\circ} \mathrm{C}$. The effect of the vesicular $\mathrm{H}^{+}$-ATPase inhibitors bafilomycin $\mathrm{A} 1$ or concanamycin A was tested in slices preincubated in the presence of the drug at $34^{\circ} \mathrm{C}$ for $2 \mathrm{hr}$ and $30 \mathrm{~min}$. For this type of experiment, control slices were incubated at $34^{\circ} \mathrm{C}$ on the same day in the absence of drugs.

Electrophysiology. Glial cells and neurons were identified using infrared videomicroscopy. Whole-cell patch-clamp recordings were performed from pyramidal neurons in the subiculum and CA1 regions. For recordings performed near the resting membrane potential $(-80 \mathrm{mV})$, patch pipettes were filled with an internal solution containing (in $\mathrm{mm}$ ): $120 \mathrm{~K}$-gluconate, $15 \mathrm{Na}$-gluconate, $3 \mathrm{MgCl}_{2}$, 0.2 EGTA, 10 HEPES, 10 phosphocreatine, $4 \mathrm{ATP}$, and $0.3 \mathrm{GTP}, \mathrm{pH} 7.2-7.4$. For recordings at +40 $\mathrm{mV}$, the internal solution contained (in mM): 100 Cs-gluconate, 10 TEA$\mathrm{Cl}, 3 \mathrm{~N}$-ethyl bromide quaternary salt, 44 -AP, $4 \mathrm{NaCl}, 1 \mathrm{MgCl}_{2}, 10$ BAPTA, 10 HEPES, 5 phosphocreatine, 2 ATP, 0.3 GTP, pH 7.2-7.4. I-V curves of transient currents were obtained with an extracellular solution containing $1 \mathrm{mM} \mathrm{CaCl}_{2}, 1 \mathrm{~mm} \mathrm{MgCl}_{2}$, and $0.5 \mu \mathrm{M}$ TTX and an intracellular solution containing (in mM): $120 \mathrm{CsCl}, 10 \mathrm{TEA}-\mathrm{Cl}, 0.2$ EGTA, 20 HEPES, 10 phosphocreatine, 4 ATP, 0.3 GTP, pH 7.2-7.4. For all recordings performed with $\mathrm{K}$-gluconate or Cs-gluconate in the pipette, potentials were corrected for a junction potential of $-10 \mathrm{mV}$.

To stimulate single glial cells in hippocampal slices while recording from pyramidal cells, the tip of a second patch pipette was brought in contact with the soma of a glial cell located at $10-50 \mu \mathrm{m}$ from the soma or the apical dendrite of the recorded neuron. A gentle suction was then applied to this pipette to stimulate mechanically the glial cell. In some cases, this led to the formation of a gigaseal, which allowed us to perform subsequently a whole-cell recording to confirm the identity of glial cells on the basis of electrophysiological properties (see Fig. $5 A$, inset).

Data collection and analysis. Whole-cell recordings were obtained using two patch-clamp amplifiers (Axopatch 200A and 200B; Axon Instruments, Union City, CA) and filtered at $1-2 \mathrm{kHz}$. Series resistances were monitored throughout the experiments, but they were not compensated. Digitized data were acquired at $10 \mathrm{kHz}$ and analyzed off-line using pClamp 8.2 and 9.0 software (Axon Instruments).

The $10-90 \%$ rise time of slow transient currents (STCs) was first measured from recordings performed in slices pretreated with $\mathrm{H}^{+}$-ATPase inhibitors, in which neuronal synaptic currents were abolished (see Results). In this condition, only $2.5 \%$ of the spontaneous transient currents had a rise time $<10 \mathrm{msec}$. For all recordings, we thus considered transient currents with rise times $>10 \mathrm{msec}$ as STCs of nonsynaptic origin.

The mean frequency of STCs was determined for each neuron as the number of events per minute during a period from 2 to $15 \mathrm{~min}$. For pharmacological studies, the low frequency of these currents imposed to represent the frequency as a function of time as follows. First, events were sorted using 3 min periods (bins). Second, each bin was then normalized to the bin showing the maximum value (i.e., the maximum bin varied in time from cell to cell). Finally, a normalized histogram for cells recorded in similar conditions was averaged.

The statistical significance of the difference between means of two samples was computed with Student's $t$ test. When at least three samples were compared, an ANOVA test was first used to show that the samples came from distributions with different means; then, Dunnett or Tukey tests were used on each pair of samples. The probability that data from two distributions belong to the same population was determined with the Kolmogorov-Smirnov test. Statistical data are given as mean \pm SEM. $n$ refers to the number of cells, unless otherwise stated.

Drugs. TTX, bafilomycin A1, D-serine, D-(-)-2-amino-5-phosphonopentanoic acid (D-AP-5), 2,3-dioxo-6-nitro-1,2,3,4-tetrahydrobenzoquinoxaline-7-sulfonamide (NBQX), (RS)-3,5-dihydroxyphenylglycine (DHPG), DL-threo- $\beta$-benzyloxyaspartate (TBOA), (2S)-2-amino-2-[(1S,2S)2-carboxycycloprop-1-yl] propanoic acid (LY341495), dizocilpine/ (5S,10R)-(+)-5-methyl-10,11-dihydro-5H-dibenzo[a,d] cyclohepten5,10-imine maleate (MK-801), ( $S$ )- $(+)$ - $\alpha$-amino-4-carboxy-2-methylbenzeneacetic acid (LY367385), and 2-methyl-6-(phenylethynyl)pyridine hydrochloride (MPEP) were purchased from Tocris Cookson (Bristol, UK). Concanamycin A and $\mathrm{PGE}_{2}$ were purchased from Calbiochem (La Jolla, CA) and Biomol (Plymouth, PA), respectively.

\section{Results}

\section{Slow transient and tonic NMDA currents in hippocampal} pyramidal neurons

We studied excitatory currents of pyramidal neurons recorded in the CA1 and subiculum regions of the rat hippocampus maintained in acute slices. When we held pyramidal neurons near their resting membrane potential and in the absence of external magnesium to prevent the voltage-dependent block of glutamate receptors of the NMDA subtype (Mayer et al., 1984; Nowak et al., 1984), we observed spontaneous STCs (Fig. 1A). In slices from 11- to 17 -d-old rats, the polarity of the STCs reversed near $0 \mathrm{mV}$, and outward currents were recorded at $+40 \mathrm{mV}$ (Fig. $1 \mathrm{~B}$ ), as expected for non-selective cationic channels. Their amplitude ranged from 10.1 to $1122.9 \mathrm{pA}$ (mean, $104.9 \pm 13 \mathrm{pA} ; 121$ events; $n=18$ ). These currents were observed at low frequency in the majority of the recorded neurons and even in the presence of 0.5-1 $\mu \mathrm{M}$ TTX, which blocks action potential propagation in the neuronal network (Fig. $1 B, C$ ) (mean, $0.82 \pm 0.15$ events $/ \mathrm{min}$ ). Their kinetics was slower than that of synaptic currents with a $10-90 \%$ rise time of $135.5 \pm 20.1 \mathrm{msec}$ (Fig. $1 B$, inset, $D$ ) (range, $11.6-2058 \mathrm{msec}$ ) and a decay time constant of $608.2 \pm 216.45$ msec (range, 92.7-7021.8 $\mathrm{msec}$ at $+40 \mathrm{mV}$ ). The rise time was thus used to distinguish between synaptic and nonsynaptic currents (see Materials and Methods).

Coapplication of D-AP-5 and NBQX, two competitive antagonists of NMDA and non-NMDA glutamate receptors, respectively, entirely blocked STCs (Fig. $1 A)(n=3)$. However, they persisted when $20 \mu \mathrm{M}$ NBQX was bath applied alone $(n=$ 4; data not shown) but were abolished by $50 \mu \mathrm{M}$ D-AP-5 (Fig. $1 E 1, E 2)$ or by $20 \mu \mathrm{M} M K-801$, a noncompetitive antagonist of NMDA receptors (NMDARs) $(n=4$; data not shown). Bath application of D-AP-5 also blocked a tonic current in pyramidal neurons (Fig. 1E1). The tonic conductance blocked by 50 $\mu \mathrm{M}$ D-AP-5 had a mean value of $378.9 \pm 87.8 \mathrm{pS}$. Increasing the concentration of D-AP- 5 to $300 \mu \mathrm{M}$ or the addition of 20 $\mu \mathrm{M}$ NBQX did not further change the holding current (Fig. 1 E3). The low frequency of STCs and their variable amplitude made it difficult to analyze in more detail their voltage depen- 
dency in standard recording conditions. However, current frequency could be markedly increased during pharmacological manipulations (see Fig. 5, inset), and in these conditions, the average amplitude of the currents showed the voltage-dependent block by extracellular magnesium ions expected for NMDA receptors (Fig. $2 B$, inset). We concluded that activation of NMDA receptors induced spontaneous STCs as well as a tonic current in hippocampal pyramidal neurons.

The activation of NMDA receptors requires the binding of two coagonists (i.e., glutamate as well as glycine or Dserine) (Johnson and Ascher, 1987; Schell et al., 1995; Mothet et al., 2000). Because we observed a tonic current mediated by NMDA receptors (see above), the presence of ambient glutamate and glycine/D-serine suggests that the transient currents could be produced by an additional transient release of any of the agonists. Bath application of $\mathrm{D}$-serine $(0.3-1 \mathrm{~mm})$ did not change either the frequency of the STCs $(n=3)$ or the amplitude of the holding membrane current ( $n=5$; data not shown). This observation indicates that glycine/Dserine sites of NMDA receptors were saturated in our experimental conditions. Thus, tonic and STCs were produced by a release of glutamate or of another endogenous agonist of the glutamate binding site. The lack of effect of D-serine also excludes the involvement of NMDA receptors containing NMDAR3 subunits, because these receptors, unlike other NMDA receptors, are blocked by Dserine (Chatterton et al., 2002;Sasaki et al., 2002).

Although most of our recordings were performed in slices from 11- to 17-d-old rats (see above), we also observed STCs in slices from 24- to 40-d-old animals. Indeed, the frequency of the spontaneous STCs $(0.41 \pm 0.11$ events/min; $n=24)$, their rise time $(102 \pm 18 \mathrm{msec} ; n=17)$, and their amplitude $(100 \pm 27.4 \mathrm{pA} ; n=$ 17) were not significantly different between these two postnatal developmental stages (Student's $t$ test; $p>0.05$ ). Therefore, it seems that STCs do not occur only during the early maturation of the hippocampus but persist beyond the end of the first postnatal month.

\section{STCs result from a glutamate release from glial cells}

The slow and variable kinetics of STCs suggested that they were not caused by a classical form of neuronal release. Therefore, we looked for the source of glutamate-generating STCs. We first tested whether the occurrence of STCs could be increased by pharmacological manipulations known to activate glial cells in hippocampal slices. Agonists of type I metabotropic glutamate receptors or $\mathrm{PGE}_{2}$ have been shown to induce
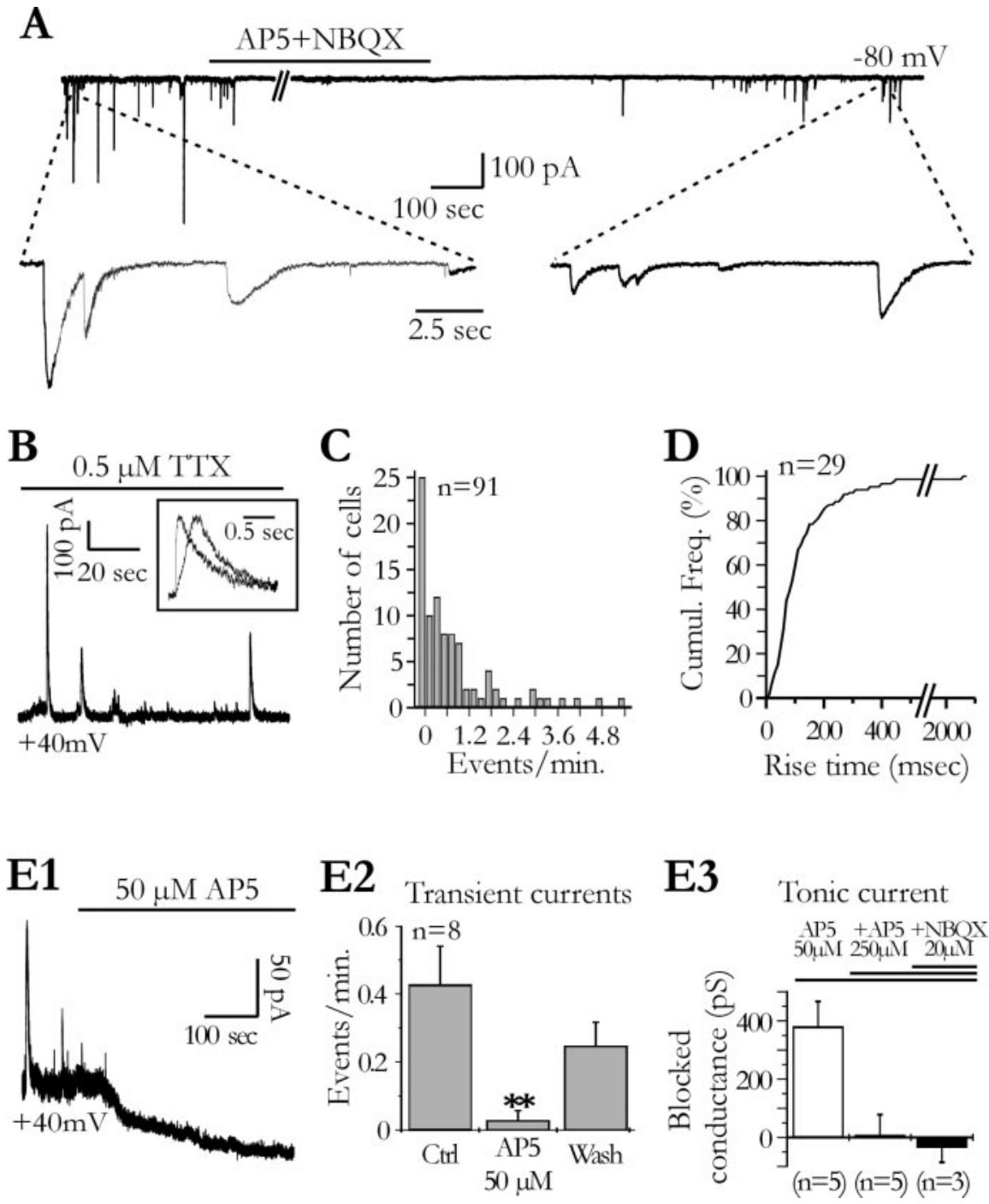

Figure 1. Slow transient and tonic NMDA receptor-mediated currents in hippocampal pyramidal cells. A, Spontaneous slow measured in our sample. $B$, In another neuron, spontaneous slow transient currents are recorded at $+40 \mathrm{mV}$ in the presence of currents normalized in amplitude are shown in the inset to illustrate the variability of the kinetics. C, Distribution of the 列 (1) presence of TTX. E, Bath application of D-AP-5 abolishes slow transient currents and a tonic current. E1, Effects of $50 \mu \mathrm{M}$ D-AP-5 on the membrane current of a CA1 pyramidal cell recorded at $+40 \mathrm{mV}$. E2, Effect of D-AP-5 on the frequency of the slow transient currents (ANOVA test; $p<0.01$ ). E3, Mean tonic conductance blocked by $50 \mu \mathrm{M} D-A P-5$ and the absence of effect of a higher concentration of D-AP-5 and of NBQX. Ctrl, Control; Wash, recovery after washing out D-AP-5.

glutamate release from hippocampal astrocytes (Porter and McCarthy, 1996; Pasti et al., 1997; Bezzi et al., 1998). When we bath applied low concentrations of the type I metabotropic receptor agonist DHPG $(10 \mu \mathrm{M})$, we observed a significant increase in the frequency of the STCs (Fig. $2 A$, left). The $10-$ $90 \%$ rise time and the amplitude of the slow currents recorded at $-80 \mathrm{mV}$ before and during DHPG were not different (Fig. $2 B)$. Similarly, bath application of 5-20 $\mu \mathrm{M} \mathrm{PGE}_{2}$ also increased the STC frequency (Fig. 2A, right).

Finally, to exclude the involvement of a glutamate vesicular release from neurons, we tested the effects of inhibitors of vacuolar $\mathrm{H}^{+}$-ATPases. This pump of the vesicular membrane establishes the proton gradient, which drives transmitter uptake into synaptic vesicles (Drose and Altendorf, 1997). Pretreatment of 

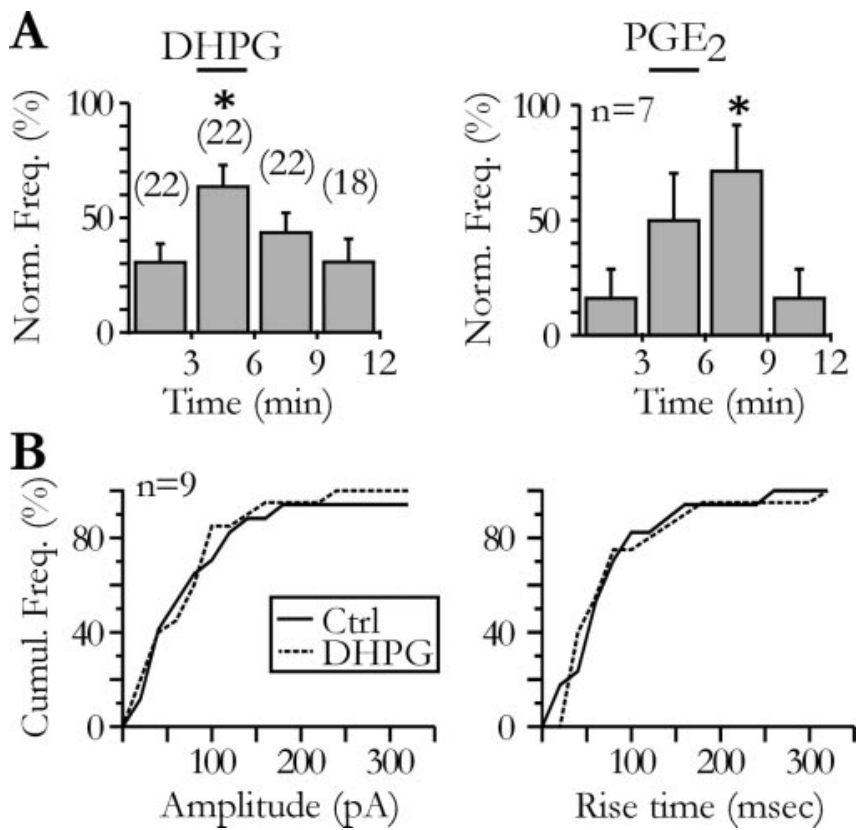

Figure 2. $D H P G$ and $P G E_{2}$ increase the frequency of the slow transient currents recorded in pyramidal neurons. A, Effect of bath applications of DHPG (10 $\mu \mathrm{m}$; left) and PGE 2 (5-20 $\mu \mathrm{m}$; right) on the frequency of the slow transient currents in neurons held at $-80 \mathrm{mV}$ (ANOVA test; $p<0.05$ ). Numbers in parenthesis above the bars of the left histogram refer to the number of tested pyramidal neurons. $B$, Comparison of the cumulative frequency distributions of the amplitude (left) and of the 10-90\% rise time (right) of the STCs recorded before (Ctrl) and during the application of DHPG $(10 \mu \mathrm{m})$ for nine neurons showing both spontaneous and agonistevoked STCs (Kolmogorov-Smirnov tests; $p>0.05$ ). Ctrl, Control.

hippocampal slices during $2 \mathrm{hr}$ and $30 \mathrm{~min}$ with $4 \mu \mathrm{m}$ bafilomycin $\mathrm{A} 1$ or $2 \mu \mathrm{M}$ concanamycin $\mathrm{A}$ at $34^{\circ} \mathrm{C}$ abolished spontaneous synaptic currents as well as those evoked by increasing the extracellular potassium concentration from 2.5 to $10 \mathrm{~mm}$ (Fig. $3 \mathrm{~A}$ ) or by stimulating the Schaffer collaterals (Fig. $3 B$, inset). STCs were observed in 12 of 14 pyramidal cells tested after $\mathrm{H}^{+}$-ATPase inhibitor pretreatment ( 12 slices, 6 rats). The rise time distribution of all currents recorded in treated slices did not differ from that of STCs recorded in control slices (Fig. 3C, left) (see Materials and Methods). More than $97 \%$ of the currents recorded in treated slices had a rise time $>10 \mathrm{msec}$ and were therefore much slower than the miniature EPSCs (mEPSCs) recorded in nontreated slices (Fig. 3C, right).

These results support the idea that STCs recorded in pyramidal neurons result from a glutamate release from glial cells. To demonstrate the glial origin of the release more directly, we stimulated mechanically glial cells visually identified in the slices (see Materials and Methods) and located 10-50 $\mu \mathrm{m}$ from the soma or the apical dendrite of the recorded neuron. Such mechanical stimulations have been used to activate glial cells in cultures, slices, and intact retina (Newman and Zahs, 1997; Araque et al., 1998a; Zonta et al., 2003). The top trace in Figure $4 A$ illustrates STCs induced in a pyramidal cell by the mechanical stimulation of a single nearby glial cell in the presence of TTX. This stimulation could rarely be repeated more than once on the same glial cell. However, it was possible to activate sequentially several glial cells to trigger STCs in the same single pyramidal neuron, the frequency of the STCs increasing significantly within $1-5 \mathrm{sec}$ after the mechanical stimulation (Fig. 4A). The 10-90\% rise time of these STCs evoked by mechanical stimulation of glial cells had a mean value of $142.2 \pm 47.1 \mathrm{msec}(n=7$ recorded pyramidal neurons; $n=8$

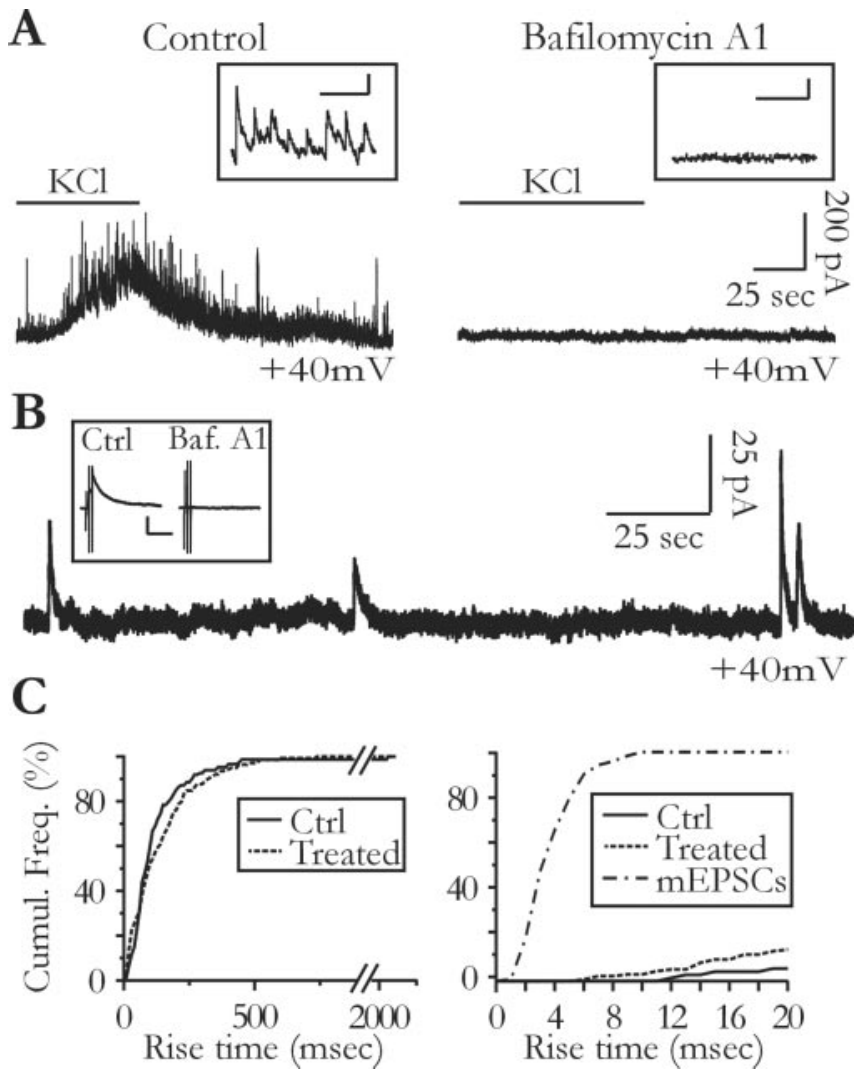

Figure 3. Slow transient currents persist in the absence of neuronal vesicular release. $A$, Preincubation of the slice with the vacuolar $\mathrm{H}^{+}$-ATPases inhibitor bafilomycin $\mathrm{A} 1$ ( $4 \mu \mathrm{m}$; right) inhibits the frequency increase of synaptic currents induced by $10 \mathrm{~mm}$ extracellular potassium normally observed in control slices (left). The insets show a portion of the traces during the increase in potassium concentration at a faster time scale. Calibration: $100 \mathrm{msec}, 50 \mathrm{pA}$. $B$, Preincubation of the slices with $4 \mu \mathrm{m}$ bafilomycin $\mathrm{A} 1$ does not inhibit the slow transient currents. The inset shows that incubation of the slices with bafilomycin A1 (Baf. A1) abolishes the synaptic responses, which can be evoked by the electrical stimulation of Schaffer collaterals in nontreated slices (Ctrl). The stimulation intensity for the control and the pretreated slice is 0.4 and $1 \mathrm{~mA}$, respectively. Calibration: $500 \mathrm{msec}, 100 \mathrm{pA}$. C, Preincubation of the slices with $4 \mu \mathrm{m}$ bafilomycin $\mathrm{A} 1$ or $2 \mu \mathrm{m}$ concanamycin A does not change the kinetics of the slow transient currents (left: Ctrl, same control plot as in Fig. 1D; Treated, 12 pretreated slices, $n=12$ cells; Kolmogorov-Smirnov test; $p>0.05$; right: mEPSC distribution obtained from 3 neurons recorded in nontreated slices and superimposed with the beginning of the STC distributions shown on the right panel).

stimulated glial cells), which did not differ from that of spontaneous STCs (Student's $t$ test; $p>0.05$ ). We then tested whether evoked STCs were sensitive to the noncompetitive antagonist of NMDA receptor MK-801 (20 $\mu \mathrm{M})$. Five pyramidal cells were recorded first in the absence of MK-801, and one or two glial cells were mechanically stimulated. In these conditions, five of the eight stimulated glial cells evoked STCs. MK-801 was then bath applied for at least 3 min before stimulating other glial cells. In the presence of the NMDA receptor antagonist, an STC was observed in only 1 of 13 tested glial cells. Finally, we performed mechanical stimulation experiments in slices pretreated with $\mathrm{H}^{+}$-ATPase inhibitors. As in control slices, the probability to record STCs in pyramidal neurons was significantly increased by mechanical stimulations of visually identified glial cells (Fig. $4 B$, left). In contrast, similar mechanical stimulations of visually identified neurons did not change the frequency of STCs (Fig. 4B, right). These results indicate that the release mechanism evoking STCs in pyramidal neurons differs from classical neuronal 
A

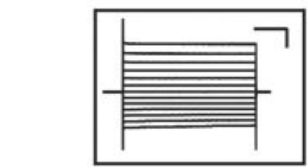

\section{Control}
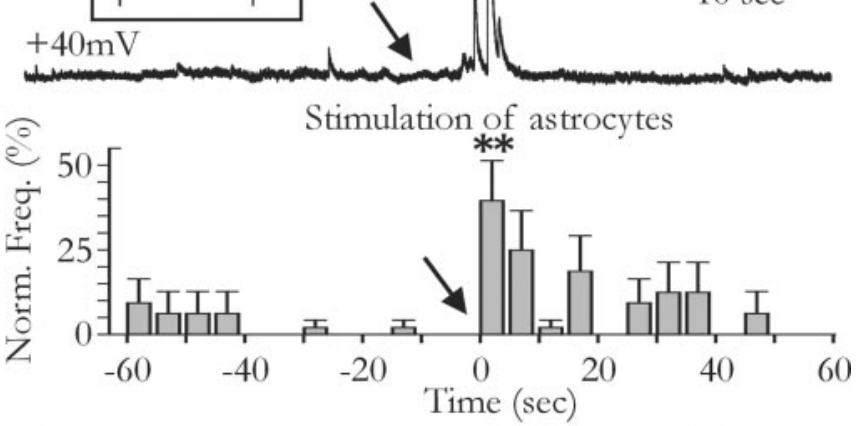

B After inhibiting the vesicular $\mathrm{H}^{+}$-ATPase
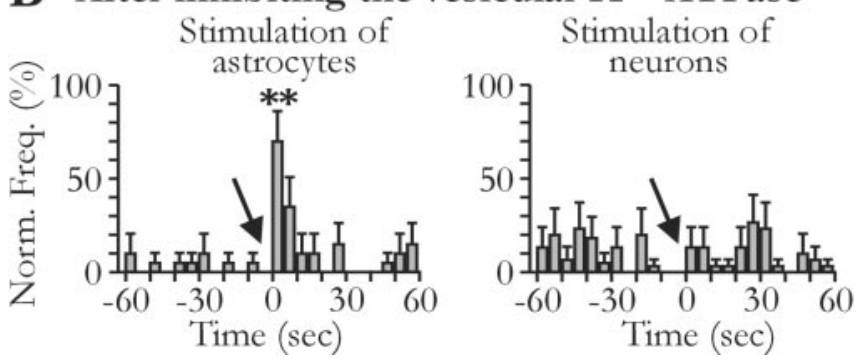

Figure 4. Mechanical stimulations of glial cells induce slow transient currents in hippocampal pyramidal neurons. $A$, The top trace illustrates slow transient currents induced by the mechanical stimulation (arrow, Mech. stim.) with a patch pipette of a single glial cell located close to the recorded neuron $(<50 \mu \mathrm{m})$. The inset illustrates a voltage-clamp recording in response to pulses from -150 to $-30 \mathrm{mV}$ of the glial cell stimulated mechanically during the recording of this neuron (resting membrane potential, $-91 \mathrm{mV}$ ). Calibration: $100 \mathrm{msec}, 0.5 \mathrm{nA}$. The histogram shows the grouped data for 11 neuronal recordings, during which a total of 23 glial cells was stimulated. The frequency of the transient currents increased significantly during the 5 sec after glial cell stimulations (ANOVA test; $p<0.001$ ). B, Effect of mechanical stimulations of single glial cells (left) and neurons (right) after preincubation of the slices with $4 \mu \mathrm{m}$ bafilomycin A1 or $2 \mu \mathrm{m}$ concanamycin A. Note that the frequency of the transient currents does not increase when neurons are mechanically stimulated (left: 12 stimulated glial cells and 4 recorded neurons; right: 11 stimulated neurons and 7 recorded neurons; ANOVA test, $p<0.001$ and $p>0.05$, respectively).

vesicular release and identify glial cells as the source of glutamate.

Glial glutamate release and ambient glutamate concentration As described in Fig. 1, NMDA receptors are also responsible for a tonic current in pyramidal neurons. Jabaudon et al. (1999) previously reported that blocking glutamate transporters with TBOA unmasks a release of glutamate by glial cells, which generates a tonic NMDA current in neurons of organotypic hippocampal cultures. It is therefore possible that in acute slices, the glutamate generating the tonic and the STCs originates from a common source (i.e., glial cells). Figure 5 shows that bath application of $100 \mu \mathrm{M}$ TBOA induced a tonic current in pyramidal neurons recorded in acute slices. This TBOA-induced tonic current had an amplitude of $377.6 \pm 54.9 \mathrm{pA}(n=17)$ when recorded at $+40 \mathrm{mV}$ in the presence of TTX. It was also observed in slices pretreated with $\mathrm{H}^{+}$-ATPase inhibitor (i.e., in the absence of neuronal vesicular release) $(272.9 \pm 20 \mathrm{pA} ; n=3 ; p>0.05)$. In the presence of the NMDA receptor antagonist D-AP-5 (150-300 $\mu \mathrm{M})$, the amplitude of the current induced by TBOA at $+40 \mathrm{mV}$ was $7.6 \pm 7.5 \mathrm{pA}(n=3)$. When applied at the maximum of the
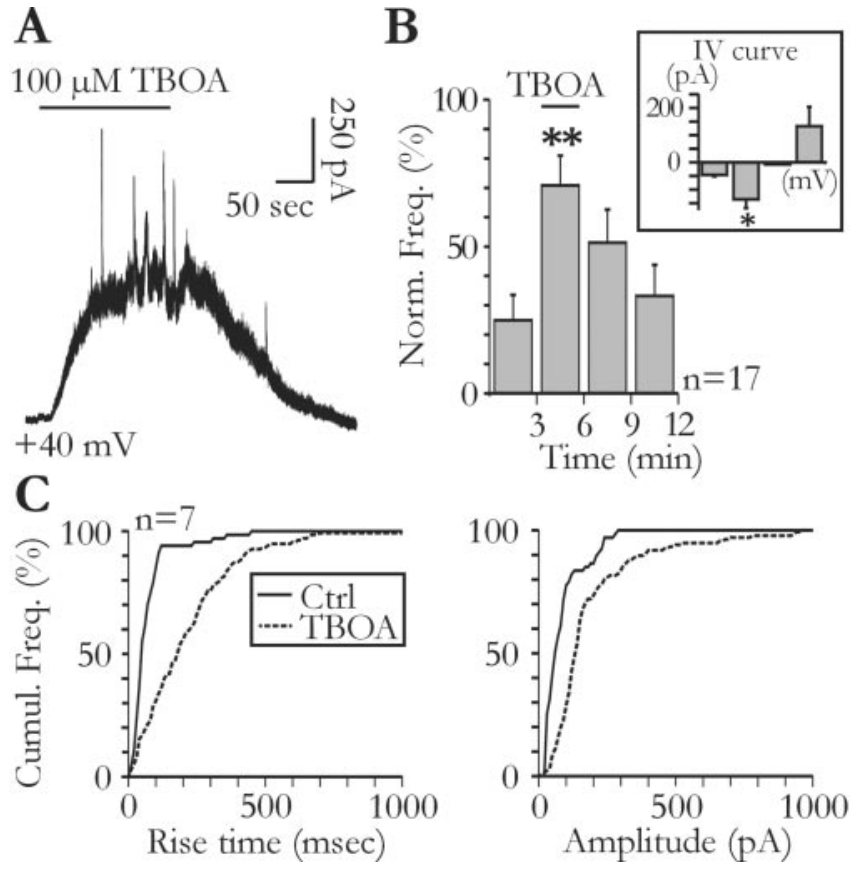

Figure 5. Glial glutamate release contributes to ambient glutamate concentration. $A$, Tonic and slow transient currents are unmasked by bath application of TBOA (100 $\mu \mathrm{M})$. $B$, Effect of TBOA on the frequency of slow transient currents (ANOVA test; $p<0.001$ ). The voltage dependency of slow transient currents during the application of TBOA was obtained with $1 \mathrm{~mm} \mathrm{Ca}^{2+}$ and $1 \mathrm{~mm} \mathrm{Mg}^{2+}$ in the extracellular solution (inset). The bars from left to right correspond to the mean amplitude of transient currents measured at $-70,-30,0$, and $+30 \mathrm{mV}(n=3$; Student's $t$ test, $p<0.05$ ). C, The cumulative distributions of the rise time (left) and amplitude (right) of the slow transient currents are shifted to the right during TBOA application (Kolmogorov-Smirnov test; $p<0.001)$. Ctrl, Control.

TBOA-induced current, D-AP-5 (50 $\mu \mathrm{M} ; n=6)$ fully reversed the effects of the uptake blocker and also blocked the tonic current present in the absence of TBOA (see above) (Fig. 1E). Consequently, the mean amplitude of the current bloked by AP-5 $(320.1 \pm 60.5 \mathrm{pA})$ exceeded that of the current induced by TBOA $(269.5 \pm 57.5 \mathrm{pA})$. In the majority of the tested cells, this tonic current was accompanied by an increase in the frequency of the STCs (Fig. $5 A, B$ ). One possible explanation for this increase is that by elevating ambient glutamate concentration, TBOA enhances the activation of glial glutamate receptors, thereby increasing the frequency of the transient currents (Fig. 2A). However, TBOA still induced a frequency increase of the STCs in the presence of NBQX (20 $\mu \mathrm{M} ; n=3)$, the group I metabotropic glutamate receptor antagonists LY367385 (100 $\mu \mathrm{M})$ and MPEP (50 $\mu \mathrm{M} ; n=3$ ), or the large spectrum metabotropic glutamate receptor antagonist LY341495 (100 $\mu \mathrm{M} ; n=4)$. Alternatively, blockade of glutamate transporters could unmask the release of glutamate from remote sites, which is normally not detected by pyramidal neurons when transporters actively remove glutamate from the extracellular space. If this were true, transient currents appearing in the presence of TBOA should be, on average, slower than those recorded in control conditions, because the kinetics of the glutamate concentration changes, arising from remote release sites, should be slowed by the effect of diffusion. Indeed, the rise time distribution of the transient currents was shifted toward slower values during TBOA application (Fig. 5C, left). The amplitude distribution was also shifted toward larger values in the presence of TBOA (Fig. $5 C$, right). Therefore, after blockade of glutamate transporters, pyramidal neurons are sensitive to the activity of more distant release sites than in 


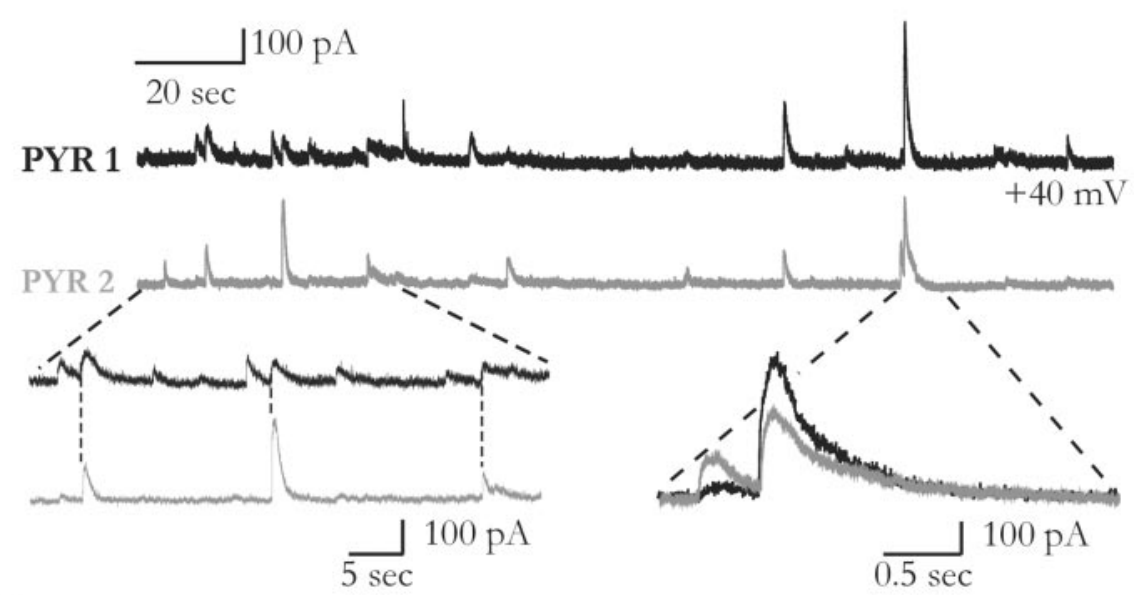

\section{B Intervals between currents recorded in two neurons}

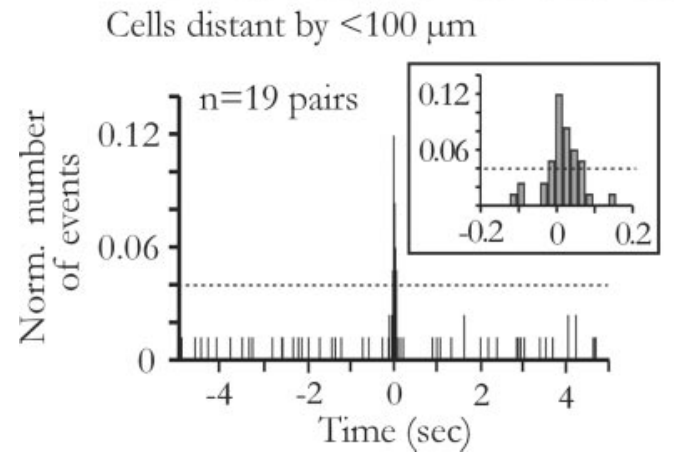

Figure 6. Glutamate released from glial cells synchronizes neuronal activity. A, Slow transient currents are synchronized in two different pyramidal cells recorded simultaneously in the presence of TTX. Note the high degree of precision of the synchronization. $B$, Normalized distributions of current time intervals in neuronal pairs for which the somata were distant by less (left) or more (right) than $100 \mu \mathrm{m}$. The noise level is indicated by the dashed line. Note that synchronized events occur only when neurons are distant by $<100 \mu \mathrm{m}$ (inset). Number of events: left, 84; right, 43.

control conditions. It is possible that at least part of the tonic NMDA current, which increases dramatically in TBOA, results from the summation of STCs originating from very distant release sites.

\section{Glutamate released from glial cells synchronizes neighboring pyramidal neurons}

Despite their relatively low frequency, STCs can occur simultaneously in adjacent pyramidal neurons. Figure $6 \mathrm{~A}$ illustrates the results of an experiment during which two CA1 neurons with somata distant by $<100 \mu \mathrm{m}$ were recorded simultaneously. During the recording period of $3 \mathrm{~min}$, several currents appeared almost simultaneously in this pair of neurons. To analyze further this synchronization, we measured the delay between the onset of each current recorded in one neuron and those of all currents appearing in the other neuron of each pair during 2-5 min. The distribution of these delays obtained from all pairs distant by $<100 \mu \mathrm{m}$ showed a clear peak centered at $\sim 0 \mathrm{sec}$ (Fig. $6 B$, left). This was not the case for the interval distribution of the currents measured from pairs of pyramidal neurons distant by $>100 \mu \mathrm{m}$ (Fig. $6 \mathrm{~B}$, right). To estimate the time interval in which two events could be considered synchronized, we first normalized each of these two distributions respectively to their total number of intervals comprised between $\pm 5 \mathrm{sec}$ at $\sim 0$. We then calculated the mean \pm 2 SDs of the interevent intervals for pairs distant by $>100 \mu \mathrm{m}$, where no peak was apparent and considered this value as the noise level (Fig. $6 B$; dashed lines). In the

distribution shown in Figure $6 B$ (left), 42\% of the interevent intervals measured for the 19 pairs of neurons distant by $<100 \mu \mathrm{m}$ were above the noise level and within a time window of $100 \mathrm{msec}$. Among these 19 pairs, $53 \%$ showed at least one synchronized event (i.e., two currents with a time interval $<100$ $\mathrm{msec})$. All of these experiments were performed in the presence of TTX, indicating that action potential propagation in the neuronal network was not needed for this synchronization to occur. The relative short delay between synchronized currents is also incompatible with the involvement of active propagation of calcium waves in astrocytes that occur at slow speeds (50 $\mu \mathrm{m} / \mathrm{sec})$ (Haydon, 2001, and Newman, 2003). Rather, this synchronization appeared to rely on local nonpropagated events and was a function of the distance between the recorded neurons. Indeed, only one of 15 pairs had synchronized currents when their somata were separated by $>100$ $\mu \mathrm{m}$. These data thus indicate that synchronized currents result from a local release of glutamate from a single glial cell detected by two adjacent neuronal processes.

\section{Discussion}

Our results show that glial cells spontaneously release glutamate and thereby excite pyramidal neurons in acute hippocampal slices. This release occurs in the absence of neuronal activity and in the absence of neuronal vesicular release of transmitters. Our findings are therefore in agreement with previous reports of spontaneous activities of astrocytes occurring in the absence of neuronal activity in brain slices (Parri et al., 2001; Aguado et al., 2002; Parri and Crunelli, 2003). This does not exclude a role of neurons in regulating astrocyte activity and therefore their glutamate release. Indeed, glial cells are endowed with a large repertoire of receptors for many neurotransmitters and, for instance, astrocytes can be mobilized by the activation of their metabotropic glutamate receptors in response to neuronal activity (Porter and McCarthy, 1996; Pasti et al., 1997; Bezzi et al., 1998). Accordingly, we observed that DHPG, the agonist of group I metabotropic glutamate receptors, increases the frequency of STCs.

Slow excitatory currents mediated by NMDA receptors have been recently described in hippocampal and thalamic neurons recorded in acute slices obtained from rodents younger than P14 (Parri et al., 2001; Demarque et al., 2002). In the hippocampus, these currents had extremely slow kinetics and were attributable to a SNARE-independent glutamate release from an unidentified source (Demarque et al., 2002). In the thalamus, the currents were detected in neurons localized on the path of propagating glia calcium waves and therefore most likely result from a glutamate release correlated with glial cell calcium oscillations (Parri et al., 2001). In contrast with the above mentioned studies, the STCs described here were recorded in neurons from more mature animals aged P11$\mathrm{P} 40$. The high input resistance of immature neurons probably 
makes the detection of these currents easier; however, by blocking most of the potassium conductance and by reducing as much neuronal synaptic noise as possible, we could observe STCs in the majority of the recorded neurons, including mature neurons $(72.5 \%$ of neurons at P11-P17 and $70.8 \%$ of neurons at $\mathrm{P} 24-\mathrm{P} 40)$. Our results therefore indicate that this form of communication from glia to neurons is not restricted to early stages of the brain postnatal development and persists after the peak of synaptogenesis.

Astrocytes can release glutamate through different mechanisms, including a calcium-dependent, possibly vesicular, form of release (Parpura et al., 1994; Pasti et al., 1997, 2001; Araque et al., 1998a, 2000; Bezzi et al., 1998, 2004; Parpura and Haydon, 2000), the reverse operation of glutamate transporters (Nicholls and Attwell, 1990; Longuemare and Swanson, 1995), the opening of large pore channels (Kimelberg et al., 1990, 1995; Duan et al., 2003; Ye et al., 2003), and the activity of the cystine-glutamate antiporter (Pow, 2001; Baker et al., 2002). Our present study did not aim at identifying the actual mechanism by which astrocytes release glutamate. However, our observation that TBOA increases STC frequency and enhances the tonic NMDA conductance does not support an involvement of glutamate transporters operating in a reverse mode (Nicholls and Attwell, 1990; Rossi et al., 2000). Bath applications of glutamate metabotropic receptor agonists and of $\mathrm{PGE}_{2}$ as well as mechanical stimulations, which increase the frequency of STCs, were shown previously to trigger intracellular calcium transients in astrocytes (Porter and McCarthy, 1995; Newman and Zahs, 1997; Pasti et al., 1997; Araque et al., 1998a; Bezzi et al., 1998; Zonta et al., 2003). Therefore, these results would rather support the involvement of a calciumdependent release mechanism. In contrast, experiments with bafilomycin A1 and concanamycin A showed that inhibiting vacuolar $\mathrm{H}^{+}$-ATPase abolished neuronal vesicular release but not STCs recorded in pyramidal neurons. This does not totally rule out the possible involvement of a vesicular release of glutamate from astrocytes, because the depletion of glutamate-containing vesicles in glial cells might require more prolonged action of these inhibitors than required for the depletion of neuronal vesicles. It is worth noting, however, that in hippocampal organotypic cultures, prolonged incubation with clostridial toxins inhibiting vesicular glutamate release does not change a glial release of glutamate (Jabaudon et al., 1999). Interestingly, this release was uncovered by blocking glutamate uptake and generated in pyramidal cells a tonic NMDA current similar to the one that we observed in acute slices. Identifying the actual mechanism by which glia release glutamate in preserved preparation will thus require additional experiments and probably the development of new experimental tools.

The kinetics of STCs evoked in pyramidal neurons by glial glutamate release is extremely variable and exceeds that of synaptic currents mediated by NMDA receptors (Figs. $1 D$, $4 C$ ). Indeed, the rising phase of NMDA receptor-mediated synaptic currents in hippocampal pyramidal neurons is close to $10 \mathrm{msec}$ (Hestrin et al., 1990). One possibility to explain the slow and variable kinetics of these currents is that NMDA receptors activated by glutamate released from glial cells are mainly extrasynaptic. Indeed, extrasynaptic NMDA receptors facing glial processes have been observed by immunogold electron microscopy on the dendrites of cortical pyramidal cells (Kharazia and Weinberg, 1999). If the release sites of astrocytes are not incorporated in anatomical structures as tight as synapses but face a more open extracellular space, diffusion of glutamate will slow down the concentration changes and also decrease the maximum concentration (Barbour, 2001) detected by extrasynaptic NMDA receptors. The wide range of kinetics of the STCs encountered in a given pyramidal neuron may reflect its ability to detect the activity of several glial release sites located at various distances as well as variability in the release kinetics. Consistent with the former hypothesis is the observation that inhibiting glutamate transporters with TBOA favors the occurrence of STCs with kinetics slower than those observed in control conditions, probably because glutamate was now able to diffuse over longer distances. This indicates that glutamate transporters regulate the number of glial release sites that are detected by pyramidal neurons. Moreover, the tonic NMDA current, which is increased by TBOA (Fig. 2) (Jabaudon et al., 1999), probably results from the diffusion of glutamate released so distantly that concentration peaks cannot be detected anymore. This suggests that ambient glutamate may result primarily from the activity of glial cells releasing glutamate through the same mechanism than the one inducing the STCs described in the present study. Activation of extrasynaptic NMDA receptors by ambient glutamate has been shown to enhance pyramidal cell excitability and regulate the inputoutput function of these neurons (Sah et al., 1989). Because micromolar concentrations of ambient glutamate, possibly from a glial origin, have been measured in vivo in the extrasynaptic space (Baker et al., 2002; Del Arco et al., 2003) and NMDA receptors $\mathrm{EC}_{50}$ for sustained application of glutamate is within 1-10 $\mu \mathrm{M}$, we propose that glutamate release from glial cells participates to the modulation of pyramidal cell excitability.

Finally, our results also indicate that STCs most often occur synchronously in neighboring pyramidal neurons. This synchronization did not arise from an electrical coupling between pyramidal neurons. If this was the case, there should be no delay between synchronized STCs, and the ratio of amplitudes between STCs recorded in two neurons should be constant. As illustrated in Figure 6, both parameters (i.e., the amplitude ratio and the delay) were quite variable. The characteristics of this synchronization suggest that it results from the activity of a single glial cell rather than from the propagation of a calcium wave within a network of astrocytes. Indeed, these waves propagate between astrocytes at speeds slower than $50 \mu \mathrm{m} / \mathrm{sec}$ (Haydon, 2001; Newman, 2003). This means that in $100 \mathrm{msec}$, the time window at which the synchronization of STCs operates, a wave would travel no more than $5 \mu \mathrm{m}$. Therefore, although we cannot exclude that glutamate is actually released during the propagation of a wave, the synchronization itself involves either very close release sites or a single release site. In any case, the degree of precision of this synchronization implies that the two synchronized pyramidal neurons have processes in close vicinity facing the glia releasing site(s). It remains to be established now which physiological and pathological conditions this local control of neuronal activity by glial cells is the most involved.

\section{References}

Aguado F, Espinosa-Parrilla JF, Carmona MA, Soriano E (2002) Neuronal activity regulates correlated network properties of spontaneous calcium transients in astrocytes in situ. J Neurosci 22:9430-9444.

Araque A, Parpura V, Sanzgiri RP, Haydon PG (1998a) Glutamatedependent astrocyte modulation of synaptic transmission between cultured hippocampal neurons. Eur J Neurosci 10:2129-2142. 
Araque A, Sanzgiri RP, Parpura V, Haydon PG (1998b) Calcium elevation in astrocytes causes an NMDA receptor-dependent increase in the frequency of miniature synaptic currents in cultured hippocampal neurons. J Neurosci 18:6822-6829.

Araque A, Parpura V, Sanzgiri RP, Haydon PG (1999) Tripartite synapses: glia, the unacknowledged partner. Trends Neurosci 22:208-215.

Araque A, Li N, Doyle RT, Haydon PG (2000) SNARE protein-dependent glutamate release from astrocytes. J Neurosci 20:666-673.

Araque A, Carmignoto G, Haydon PG (2001) Dynamic signaling between astrocytes and neurons. Annu Rev Physiol 63:795-813.

Auld DS, Robitaille R (2003) Glial cells and neurotransmission: an inclusive view of synaptic function. Neuron 40:389-400.

Baker DA, Xi ZX, Shen H, Swanson CJ, Kalivas PW (2002) The origin and neuronal function of in vivo nonsynaptic glutamate. J Neurosci 22:9134-9141.

Barbour B (2001) An evaluation of synapse independence. J Neurosci 21:7969-7984.

Bezzi P, Carmignoto G, Pasti L, Vesce S, Rossi D, Rizzini BL, Pozzan T, Volterra A (1998) Prostaglandins stimulate calcium-dependent glutamate release in astrocytes. Nature 391:281-285.

Bezzi P, Gundersen V, Galbete JL, Seifert G, Steinhauser C, Pilati E, Volterra A (2004) Astrocytes contain a vesicular compartment that is competent for regulated exocytosis of glutamate. Nat Neurosci 7:613-620.

Brockhaus J, Deitmer JW (2002) Long-lasting modulation of synaptic input to Purkinje neurons by Bergmann glia stimulation in rat brain slices. J Physiol (Lond) 545:581-593.

Chatterton JE, Awobuluyi M, Premkumar LS, Takahashi H, Talantova M, Shin Y, Cui J, Tu S, Sevarino KA, Nakanishi N, Tong G, Lipton SA, Zhang D (2002) Excitatory glycine receptors containing the NR3 family of NMDA receptor subunits. Nature 415:793-798.

Del Arco A, Segovia G, Fuxe K, Mora F (2003) Changes in dialysate concentrations of glutamate and GABA in the brain: an index of volume transmission mediated actions? J Neurochem 85:23-33.

Demarque M, Represa A, Becq H, Khalilov I, Ben Ari Y, Aniksztejn L (2002) Paracrine intercellular communication by a Ca2+- and SNAREindependent release of GABA and glutamate prior to synapse formation. Neuron 36:1051-1061.

Drose S, Altendorf K (1997) Bafilomycins and concanamycins as inhibitors of V-ATPases and P-ATPases. J Exp Biol 200:1-8.

Duan S, Anderson CM, Keung EC, Chen Y, Chen Y, Swanson RA (2003) $\mathrm{P} 2 \mathrm{X} 7$ receptor-mediated release of excitatory amino acids from astrocytes. J Neurosci 23:1320-1328.

Edwards FA, Konnerth A, Sakmann B, Takahashi T (1989) A thin slice preparation for patch clamp recordings from neurones of the mammalian central nervous system. Pflügers Arch 414:600-612.

Grosche J, Matyash V, Moller T, Verkhratsky A, Reichenbach A, Kettenmann H (1999) Microdomains for neuron-glia interaction: parallel fiber signaling to Bergmann glial cells. Nat Neurosci 2:139-143.

Haydon PG (2001) GLIA: listening and talking to the synapse. Nat Rev Neurosci 2:185-193.

Hestrin S, Nicoll RA, Perkel DJ, Sah P (1990) Analysis of excitatory synaptic action in pyramidal cells using whole-cell recording from rat hippocampal slices. J Physiol (Lond) 422:203-225.

Jabaudon D, Shimamoto K, Yasuda-Kamatani Y, Scanziani M, Gahwiler BH, Gerber U (1999) Inhibition of uptake unmasks rapid extracellular turnover of glutamate of nonvesicular origin. Proc Natl Acad Sci USA 96:8733-8738.

Johnson JW, Ascher P (1987) Glycine potentiates the NMDA response in cultured mouse brain neurons. Nature 325:529-531.

Kang J, Jiang L, Goldman SA, Nedergaard M (1998) Astrocyte-mediated potentiation of inhibitory synaptic transmission. Nat Neurosci 1:683-692.

Kharazia VN, Weinberg RJ (1999) Immunogold localization of AMPA and NMDA receptors in somatic sensory cortex of albino rat. J Comp Neurol 412:292-302.

Kimelberg HK, Goderie SK, Higman S, Pang S, Waniewski RA (1990) Swelling-induced release of glutamate, aspartate, and taurine from astrocyte cultures. J Neurosci 10:1583-1591.

Kimelberg HK, Rutledge E, Goderie S, Charniga C (1995) Astrocytic swelling due to hypotonic or high $\mathrm{K}+$ medium causes inhibition of glutamate and aspartate uptake and increases their release. J Cereb Blood Flow Metab 15:409-416.

Longuemare MC, Swanson RA (1995) Excitatory amino acid release from astrocytes during energy failure by reversal of sodium-dependent uptake. J Neurosci Res 40:379-386.

Mayer ML, Westbrook GL, Guthrie PB (1984) Voltage-dependent block by $\mathrm{Mg} 2+$ of NMDA responses in spinal cord neurones. Nature 309:261-263.

Mothet JP, Parent AT, Wolosker H, Brady Jr RO, Linden DJ, Ferris CD, Rogawski MA, Snyder SH (2000) D-serine is an endogenous ligand for the glycine site of the N-methyl-D-aspartate receptor. Proc Natl Acad Sci USA 97:4926-4931.

Nedergaard M, Takano T, Hansen AJ (2002) Beyond the role of glutamate as a neurotransmitter. Nat Rev Neurosci 3:748-755.

Nett WJ, Oloff SH, McCarthy KD (2002) Hippocampal astrocytes in situ exhibit calcium oscillations that occur independent of neuronal activity. J Neurophysiol 87:528-537.

Newman EA (2003) New roles for astrocytes: regulation of synaptic transmission. Trends Neurosci 26:536-542.

Newman EA, Zahs KR (1997) Calcium waves in retinal glial cells. Science 275:844-847.

Nicholls D, Attwell D (1990) The release and uptake of excitatory amino acids. Trends Pharmacol Sci 11:462-468.

Nowak L, Bregestovski P, Ascher P, Herbet A, Prochiantz A (1984) Magnesium gates glutamate-activated channels in mouse central neurones. $\mathrm{Na}$ ture 307:462-465.

Parpura V, Haydon PG (2000) Physiological astrocytic calcium levels stimulate glutamate release to modulate adjacent neurons. Proc Natl Acad Sci USA 97:8629-8634.

Parpura V, Basarsky TA, Liu F, Jeftinija K, Jeftinija S, Haydon PG (1994) Glutamate-mediated astrocyte-neuron signalling. Nature 369:744-747.

Parri HR, Crunelli V (2003) The role of $\mathrm{Ca}(2+)$ in the generation of spontaneous astrocytic $\mathrm{Ca}(2+)$ oscillations. Neuroscience 120:979-992.

Parri HR, Gould TM, Crunelli V (2001) Spontaneous astrocytic Ca2+ oscillations in situ drive NMDAR-mediated neuronal excitation. Nat Neurosci 4:803-812.

Pasti L, Volterra A, Pozzan T, Carmignoto G (1997) Intracellular calcium oscillations in astrocytes: a highly plastic, bidirectional form of communication between neurons and astrocytes in situ. J Neurosci 17:7817-7830.

Pasti L, Zonta M, Pozzan T, Vicini S, Carmignoto G (2001) Cytosolic calcium oscillations in astrocytes may regulate exocytotic release of glutamate. J Neurosci 21:477-484.

Porter JT, McCarthy KD (1995) GFAP-positive hippocampal astrocytes in situ respond to glutamatergic neuroligands with increases in $[\mathrm{Ca} 2+] \mathrm{i}$. Glia 13:101-112.

Porter JT, McCarthy KD (1996) Hippocampal astrocytes in situ respond to glutamate released from synaptic terminals. J Neurosci 16:5073-5081.

Pow DV (2001) Visualising the activity of the cystine-glutamate antiporter in glial cells using antibodies to aminoadipic acid, a selectively transported substrate. Glia 34:27-38.

Rossi DJ, Oshima T, Attwell D (2000) Glutamate release in severe brain ischaemia is mainly by reversed uptake. Nature 403:316-321.

Sah P, Hestrin S, Nicoll RA (1989) Tonic activation of NMDA receptors by ambient glutamate enhances excitability of neurons. Science 246:815-818

Sasaki YF, Rothe T, Premkumar LS, Das S, Cui J, Talantova MV, Wong HK, Gong X, Chan SF, Zhang D, Nakanishi N, Sucher NJ, Lipton SA (2002) Characterization and comparison of the NR3A subunit of the NMDA receptor in recombinant systems and primary cortical neurons. J Neurophysiol 87:2052-2063.

Schell MJ, Molliver ME, Snyder SH (1995) D-serine, an endogenous synaptic modulator: localization to astrocytes and glutamate-stimulated release. Proc Natl Acad Sci USA 92:3948-3952.

Schikorski T, Stevens CF (1997) Quantitative ultrastructural analysis of hippocampal excitatory synapses. J Neurosci 17:5858-5867.

Ventura R, Harris KM (1999) Three-dimensional relationships between hippocampal synapses and astrocytes. J Neurosci 19:6897-6906.

Verkhratsky A, Orkand RK, Kettenmann H (1998) Glial calcium: homeostasis and signaling function. Physiol Rev 78:99-141.

Ye ZC, Wyeth MS, Baltan-Tekkok S, Ransom BR (2003) Functional hemichannels in astrocytes: a novel mechanism of glutamate release. J Neurosci 23:3588-3596.

Zonta M, Angulo MC, Gobbo S, Rosengarten B, Hossmann KA, Pozzan T, Carmignoto G (2003) Neuron-to-astrocyte signaling is central to the dynamic control of brain microcirculation. Nat Neurosci 6:43-50. 